http://dx.doi.org/10.32929/2446-8355.2018v27n4p450-462

\title{
ENRAIZAMENTO DE DIFERENTES TIPOS DE ESTACAS DE PINHÃO MANSO EM DOIS SUBSTRATOS
}

Renata Capistrano Moreira Furlani ${ }^{1 *}$, Luiz de Souza Corrêa ${ }^{2}$, Enes Furlani Junior ${ }^{2}$, Gustavo Alves Pereira ${ }^{3}$, Amanda Pereira Paixão ${ }^{4}$

\footnotetext{
${ }^{1}$ Doutora em Agronomia - Universidade Estadual Paulista (UNESP), Faculdade de Engenharia, Ilha Solteira-SP. *E-mail: recapistrano@yahoo.com.br

${ }^{2}$ Docente do Departamento de Fitotecnia, Tecnologia de Alimentos e Sócio Economia da Universidade Estadual Paulista (UNESP), Ilha Solteira-SP.

${ }^{3}$ Docente do Departamento de Agronomia da Universidade Federal do Piauí (UFPI), Bom Jesus-PI.

${ }^{4}$ Doutoranda em Agronomia, Universidade Estadual Paulista (UNESP), Faculdade de Engenharia, Ilha SolteiraSP.
}

Recebido: 03/02/2019; Aceito: 31/10/2018

RESUMO: A escassez de combustíveis fósseis tem promovido a busca de opções para substituir esses combustíveis por semelhantes com mesma eficiência. O experimento foi realizado em casa de vegetação tipo Pad \& Fan do Departamento de Fitotecnia, Tecnologia de Alimentos e Sócio Economia da Faculdade de Engenharia - Campus de Ilha Solteira da Universidade Estadual Paulista (UNESP). O delineamento experimental utilizado foi inteiramente casualizado em esquema fatorial $3 \times 2$ (tipos de estacas $\mathrm{x}$ substrato), totalizando 6 tratamentos com 4 repetições e 10 estacas por parcela. A utilização de vermiculita permitiu a obtenção de valores para porcentagem de estacas vivas muito próximas para estacas basais $(82,5 \%)$, medianas $(80,0 \%)$ e apicais $(60,0 \%)$. As estacas basais, independentemente do tipo de substrato são aquelas que permitem uma maior obtenção de porcentagem de estacas vivas, massa da matéria seca das brotações e das raízes, comprimento dos brotos, número de brotos e número de folhas com mais de $2,0 \mathrm{~cm}$. O substrato vermiculita proporciona uma maior porcentagem de estacas vivas e número de folhas. A massa da matéria seca de raízes é maior quando da utilização do substrato areia.

Palavras-chave: Jatropha curcas L. Propagação vegetativa. Desenvolvimento vegetativo.

\section{ROOTING OF DIFFERENT TYPES OF PHYSIC NUT CUTTINGS IN TWO SUBSTRATES}

\begin{abstract}
The scarcity of fossil fuels has promoted the search options to replace these fuels with similar same efficiency. The experiment was conducted in a greenhouse type Pad \& Fan ou at the Department of Plant Sciences of the São Paulo State University-UNESP. The experimental design was completely randomized in a factorial $3 \times 2$ (types of cuttings $\mathrm{x}$ substrate), totaling 6 treatments with 4 replicates and 10 cuttings per plot. The use of vermiculite allowed to obtain values for the percentage of live cuttings very close to basal cuttings $(82.5 \%)$, median $(80.0 \%)$ and apical $(60.0 \%)$. The basal cuttings, regardless of the substrate are those that allow greater obtaining percentage of live cuttings, dry matter of
\end{abstract}


shoots and roots, shoot length, number of shoots and number of leaves with more than $2.0 \mathrm{~cm}$. The vermiculite provides a higher percentage of live cuttings and number of leaves. The dry matter of roots is greater when using the sand.

Key words: Jatropha curcas L. Vegetative propagation. Vegetative development.

\section{INTRODUÇÃO}

A escassez de combustíveis fósseis tem promovido a busca de opções para substituir esses combustíveis por semelhantes com mesma eficiência. Assim, nos últimos anos, o uso de óleo vegetal como matéria-prima para biodiesel está sendo considerado uma alternativa adequada para substituição de combustíveis fósseis. Neste segmento, se inserem várias plantas cujas sementes são produtoras de óleo, entre elas o pinhão manso (Jatropha curcas L.).

O pinhão manso vem se destacando como fonte promissora de extração de óleo. Suas sementes apresentam em média 34\% de óleo (PUTTEN et al., 2009) e o biodiesel produzido a partir desse óleo possui poder calorífico pouco inferior ao do óleo diesel, com produção de um ruído mais suave nos motores a diesel.

É uma planta que tem como possível centro de origem a América Central, mais possivelmente no México, onde se localiza maior diversidade de Jatropha curcas L (HELLER, 1996). É uma planta perene, que está em processo de domesticação, tão pouco teve um programa de melhoramento adequado que possa suportar tecnicamente e viabilizar a cultura em várias localidades. É facilmente propagada por sementes e se reproduz por polinização cruzada, gerando sementes com alto grau de variabilidade genética, o que exige o desenvolvimento de técnicas de propagação para aplicação no melhoramento da cultura.

A utilização de técnicas para preservação da viabilidade das sementes tem sido preconizada por vários autores como uma forma de evitar possíveis problemas com a obtenção de sementes para produção de mudas de boa qualidade.

Por outro lado, existem também outras tecnologias que podem ser desenvolvidas para pinhão manso, entre elas várias práticas culturais e principalmente a propagação vegetativa para produção em larga escala.

Dessa forma, faz-se necessário o desenvolvimento de pesquisas que visem à obtenção de materiais homogêneos e uma das principais formas é através da propagação vegetativa. Assim sendo, é necessário desenvolver uma tecnologia de produção para que efetivamente se produzam matrizes em grande escala e também em quantidade suficiente para distribuição para eventuais produtores.

Diante do exposto, o presente trabalho teve como objetivo o desenvolvimento de técnicas de propagação para pinhão manso através de estacas, sistemas de enxertia e sementes.

A enxertia de borbulhia e garfagem também pode ser utilizada na propagação do pinhão manso, assim como estabelecido para outras culturas. Uma das aplicações do sistema de garfagem é poder ser utilizado para aproveitar uma planta de baixa produção como porta 
enxerto para uma planta de produtividade elevada (DIAS et al., 2007). Também é recomendada a utilização de pinhão bravo (Jatropha pohliana) como porta enxerto por esta espécie apresentar maior resistência a doenças em relação ao pinhão manso (ALVES et al., 2008).

Alguns fatores como nebulização, utilização de hormônios, estado nutricional e condições adequadas para o desenvolvimento são de suma importância na utilização da técnica da enxertia (BARROS, 2007).

O objetivo do presente trabalho foi avaliar o enraizamento e o desenvolvimento de três tipos de estacas de pinhão manso em dois substratos.

\section{MATERIAL E MÉTODOS}

O experimento foi realizado em casa de vegetação tipo Pad \& Fan do Departamento de Fitotecnia, Tecnologia de Alimentos e Sócio Economia da Faculdade de Engenharia Campus de Ilha Solteira da Universidade Estadual Paulista (UNESP) (Coordenadas Geográficas Google Earth - 20²5'09.55'S e 51²0'23.33”O). Segundo a classificação de Köppen, o clima da região é do tipo Aw, apresentando temperatura média anual de $25^{\circ} \mathrm{C}$ e precipitação total anual de 1330 mm e umidade relativa média de 66\% (CENTURION, 1982).

As estacas foram retiradas no dia 29 de abril de 2011 pela manhã de plantas matrizes com dois anos de idade instaladas na Fazenda de Ensino e Pesquisa e Extensão (FEPE) da Faculdade de Engenharia, Campus de Ilha Solteira, localizada em Selvíria - MS (51 $22^{\circ}$ W e $20^{\circ} 22^{\prime} \mathrm{S}$, com altitude de $335 \mathrm{~m}$ ). As plantas foram podadas no ano anterior para emitir novas brotações. De cada planta matriz retiraram-se 2 ramos com aproximadamente $80 \mathrm{~cm}$, cada planta apresentava de 8 a 9 ramos. Os cortes foram realizados horizontalmente com tesoura de poda. As plantas matrizes foram originadas de estacas de diferentes plantas e receberam como tratos culturais poda de produção, adubação com $250 \mathrm{~kg} \mathrm{ha}^{-1}$ da fórmula 8-28-16, 3 capinas por ano e controle fitossanitário com $300 \mathrm{~mL} / 100 \mathrm{~L}$ de água do fungicida/bactericida Casugamicina (Kasumin $®)$.

O experimento foi instalado na mesma data da coleta das estacas utilizando-se como tratamentos a combinação de dois tipos de substratos e três tipos de estacas.

As estacas utilizadas foram: apical, mediana e basal com aproximadamente $20 \mathrm{~cm}$ de comprimento. Os cortes nos ramos foram realizados horizontalmente com tesoura de poda e de cada ramo originou-se apenas uma estaca basal, uma mediana e uma apical. Os $2 \mathrm{~cm}$ finais de cada ramo foram descartados antes de se proceder o corte da estaca basal. Todas as folhas existentes nas estacas foram retiradas antes do estaqueamento. O estaqueamento foi realizado em vasos plásticos perfurados com dimensões de 42 x 14 x $14 \mathrm{~cm}$ (comprimento x largura x profundidade) contendo os substratos areia grossa lavada e vermiculita de textura média. Após serem colocados na casa da vegetação, todos os vasos receberam água até a saturação do substrato. 
O delineamento experimental utilizado foi inteiramente casualizado em esquema fatorial 3 x 2 (tipos de estacas x substrato), totalizando 6 tratamentos com 4 repetições e 10 estacas por parcela.

O experimento foi irrigado por aspersão automatizada durante três minutos às 6,12 e 18 horas diariamente. $\mathrm{O}$ substrato era mantido apenas úmido e não saturado de água.

As variáveis analisadas aos 21, 32 e 75 dias após a instalação do experimento foram:

- Porcentagem de estacas vivas: determinada através da contagem do número de estacas vivas por parcela.

- Número de brotações: determinado através da contagem do número de brotações por estaca.

- Número de folhas: determinado através da contagem do número de folhas maiores que $2 \mathrm{~cm}$ por estaca.

Após 75 dias de estaqueamento as estacas foram cuidadosamente lavadas para retirar todo o substrato a elas aderido para então serem realizadas as avaliações finais.

As variáveis analisadas apenas aos 75 dias após a instalação do experimento foram:

- Comprimento dos brotos $(\mathbf{m m})$ : medição realizada com paquímetro digital de todas as brotações de cada estaca.

- Massa da matéria seca das brotações (g): foram retiradas todas as brotações das estacas de cada parcela e colocadas em saco de papel tipo kraft. Os sacos de papel foram identificados e colocados em estufa a $65^{\circ} \mathrm{C}$ até atingirem peso constante por aproximadamente 72 horas.

- Massa da matéria seca das raízes (g): foram retiradas todas as raízes das estacas de cada parcela e colocadas em saco de papel tipo kraft. Os sacos de papel foram identificados e colocados em estufa a $65^{\circ} \mathrm{C}$ por aproximadamente 72 horas até atingirem peso constante.

Os dados foram transformados em raiz quadrada de $\mathrm{x}+1$ e submetidos à análise de variância. As médias foram comparadas pelo teste de Tukey ao nível de 5\% de probabilidade utilizando-se o programa Sisvar (FERREIRA, 2011). Nas tabelas encontram-se as médias originais.

\section{RESULTADOS E DISCUSSÃO}

O número de estacas vivas ou porcentagem de pegamento é uma avaliação utilizada para verificar a eficiência de tratamentos que visam o enraizamento de estacas.

No presente trabalho, verificou-se que a porcentagem de estacas vivas (PEV) aos 21, 32 e 75 dias após o estaqueamento (d.a.e.) foi afetada pelo tipo de estaca utilizada (Tabela 1).

Desta forma, as estacas basais apresentaram maiores valores de porcentagem de estacas vivas aos 32 d.a.e. não diferindo significativamente da porcentagem de estacas vivas da porção mediana dos ramos. Da mesma forma, a porcentagem de estacas apicais vivas não diferiu estatisticamente das medianas. As estacas conduzidas em vermiculita tiveram uma 
maior porcentagem de sobrevivência quando comparadas com as conduzidas em areia, possivelmente por ser um substrato que permite alguma troca catiônica.

Tabela 1. Valores de $\mathrm{p}>\mathrm{F}$ e porcentagem de estacas vivas (PEV) obtidos para estacas de pinhão manso submetidas a tratamentos com diferentes tipos de estacas e substratos aos 21 , 32 e 75 dias. Ilha Solteira - SP, 2011. Values of $p>F$ and percentage of live cuttings (PLC) obtained for jatropha cuttings submitted to treatments with different types of cuttings and substrates at 21, 32 and 75 days. Ilha Solteira - SP, 2011.

\begin{tabular}{lccc}
\hline FV & 21 dias & 32 dias & 75 dias \\
\hline Tipo de estaca (E) & $0,0014^{* *}$ & $0,0052^{* *}$ & $0,0001^{* *}$ \\
Substrato (S) & 0,0518 & $0,0075^{* *}$ & $0,0004^{* *}$ \\
E x S & $0,0047^{* *}$ & 0,0701 & $0,0062^{* *}$ \\
\hline Estaca basal & 100,0 & $98,8 \mathrm{a}$ & 85,0 \\
Estaca mediana & 98,8 & $86,3 \mathrm{ab}$ & 63,8 \\
Estaca apical & 90,0 & $73,8 \mathrm{~b}$ & 43,8 \\
\hline Areia & 94,2 & $78,3 \mathrm{~b}$ & 54,2 \\
Vermiculita & 98,3 & $94,2 \mathrm{a}$ & 74,2 \\
\hline CV(\%) & 2,42 & 7,35 & 8,92 \\
\hline
\end{tabular}

Médias seguidas de letras iguais na coluna não diferem entre si pelo Teste de Tukey ao nível de significância de 5\%. Means followed by equal letters in the column do not differ from each other by the Tukey test at the significance level of 5\%. Source: Author's research data.

A análise do desdobramento da interação estacas e substratos para PEV indica que aos 21 d.a.e. as estacas basais e medianas proporcionaram os maiores valores de PEV no substrato areia (100\%), por outro lado, não houve diferença significativa entre os diferentes tipos de estacas no substrato vermiculita. Entretanto, as estacas apicais apresentaram os maiores valores de PEV no substrato vermiculita. Aos 75 d.a.e., tanto as estacas apicais como as medianas apresentaram maiores valores de PEV no substrato vermiculita.

Pode-se constatar também que não houve efeito significativo para os diferentes tipos de estacas quando seu estaqueamento foi feito em vermiculita e que os valores obtidos foram consideravelmente altos para os três tipos de estacas. Assim, obteve-se para estacas basais $82,5 \%$, medianas $80,0 \%$ e apicais $60,0 \%$ de estacas vivas. Tal fato torna-se uma vantagem muito grande, pois fazendo-se o estaqueamento em vermiculita pode-se aproveitar o ramo em sua totalidade, pois o pegamento será igual para todas as partes utilizadas. Por outro lado, quando o substrato utilizado foi areia, as estacas basais apresentaram os maiores valores de PEV quando comparados às estacas medianas e estas comparadas às estacas apicais, possivelmente por a areia ser um substrato totalmente inerte e as estacas basais possuírem maior quantidade de reservas quando comparadas aos demais tipos de estacas utilizadas.

De acordo com Heller (1996), alguns fatores como drenagem, aeração e composição do substrato, influenciam diretamente no desenvolvimento e no índice de sobrevivência de mudas propagadas por estaquia.

Um importante fator que interfere na sobrevivência das estacas de pinhão manso utilizadas na produção de mudas é o diâmetro da estaca. Neste sentido, Hartmann et al. (2004) relataram que o teor de carboidratos nas estacas é um dos fatores que influencia a capacidade 
de enraizamento, pois ao longo do ramo, seu teor, assim como a quantidade de substâncias promotoras ou inibidoras do enraizamento, apresentam variações, sendo este um dos motivos pelos quais as estacas colhidas de diferentes porções do ramo tendem a diferir quanto ao potencial de enraizamento. Segundo Fachinello et al. (1995), reservas mais abundantes de carboidratos resultam em maiores porcentagens de enraizamento e sobrevivência de estacas, o que explica o melhor desempenho das estacas basais quando comparadas às demais.

Tabela 1a. Desdobramento da interação dos fatores tipos de estacas e substratos para porcentagem de estacas vivas aos 21 e 75 dias após instalação. Ilha Solteira - SP, 2011. Unfolding of the interaction of the types of cuttings and substrates for the percentage of live cuttings at 21 and 75 days after installation. Ilha Solteira - SP, 2011.

\begin{tabular}{lccc}
\hline & \multicolumn{3}{c}{ Estacas (21 dias) } \\
\cline { 2 - 4 } Substrato & Basal & Mediana & Apical \\
\hline Areia & 100,0 a A & 100,0 a A & 82,5 b B \\
Vermiculita & 100,0 a A & 97,5 a A & 97,5 a A \\
\cline { 2 - 4 } & \multicolumn{3}{c}{ Estacas (75 dias) } \\
Areia & 87,5 a A & 47,5 b B & 27,5 c B \\
Vermiculita & 82,5 a A & 80,0 a A & 60,0 a A \\
\hline
\end{tabular}

Médias seguidas de letras minúsculas distintas na linha e maiúsculas na coluna diferem entre si pelo Teste de Tukey ao nível de significância de 5\%. Means followed by equal letters in the column do not differ from each other by the Tukey test at the significance level of 5\%. Source: Author's research data.

É importante salientar que ao final do experimento foi observado que todas as estacas possuíam pelo menos uma raiz. Noor Camellia et al. (2009) testaram o enraizamento de estacas de pinhão manso com a utilização de hormônios e obtiveram $74 \%$ de enraizamento.

$\mathrm{Na}$ Tabela 2 observam-se as médias de massa de matéria seca das brotações (MMSB) (g), massa da matéria seca das raízes (MMSR) (g) e comprimento dos brotos (CB) (mm) obtidos aos 75 d.a.e.

De acordo com os dados apresentados na Tabela 2 pode-se constatar que houve efeito significativo para o tipo de estaca utilizada para todas as variáveis. As estacas basais e medianas foram as que apresentaram maiores médias de massa de matéria seca das brotações (MMSB), não diferindo entre si. Para massa da matéria seca das raízes (MMSR) e comprimento dos brotos (CB), as estacas basais apresentaram os maiores valores. Moreira (2013) testando enraizamento de pinhão manso em duas épocas relatou maiores valores de massa da matéria seca da parte aérea para estacas basais. Tal fato provavelmente ocorreu devido à maior reserva de carboidratos das estacas basais. Feike et al. (2007) relatam que a produção de biomassa por estacas parece depender fortemente da massa inicial das estacas. Pode deduzir-se que a razão para isto é a diferença de assimilados que são armazenados nas estacas. Variações significativas na massa da matéria seca entre as diferentes partes do caule podem ser observadas na massa da matéria seca das folhas.

Em relação ao tipo de substrato utilizado para enraizamento, observou-se que não houve diferença significativa para os valores de MMSB e CB, já para a variável MMSR o substrato areia propiciou maiores valores para essa variável. Nesse sentido, a hipótese mais provável, é de que no substrato areia, devido a uma baixa disponibilidade de nutrientes, as raízes têm uma 
tendência de aprofundamento para buscar nutrientes, alcançando assim um maior comprimento. Por outro lado, todos os tratamentos testados propiciaram a formação de raízes ao final do período de teste experimental. A respeito do sistema radicular, Kondörfer et al. (1989) comentam que ele é parte fundamental no desenvolvimento das culturas, pois é através das raízes que as plantas conseguem suprir-se de água e nutrientes em sua quase totalidade. De modo geral, quanto maior o sistema radicular da planta, maior sua capacidade de explorar o solo e consequentemente aproveitar os nutrientes e a água disponível. O volume e a distribuição do sistema radicular são tanto mais importantes quanto menor a fertilidade do solo e maior a deficiência hídrica. O sistema radicular mais abundante também determina maior atividade microbiana, que tem influência sobre o crescimento das plantas.

Tabela 2. Valores de p>F e médias de massa de matéria seca das brotações (MMSB) (g), massa da matéria seca das raízes (MMSR) (g) e comprimento dos brotos (CB) (mm) obtidos ao final do experimento para tratamentos com tipos de estacas de pinhão manso e diferentes substratos. Ilha Solteira - SP, 2011. Values of $p>F$ and mean dry matter mass of shoots (DMMS) ( $g$ ), root dry matter mass (RDMM) ( $g$ ) and shoot length (SL) ( $\mathrm{mm}$ ) obtained at the end of experiment for treatments with types of jatropha cuttings and different substrates. Ilha Solteira - SP, 2011.

\begin{tabular}{lccc}
\hline FV & MMSB & MMSR & CB \\
\hline Tipo de estaca (E) & $0,0108^{* *}$ & $0,0002^{* *}$ & $0,0044^{* *}$ \\
Substrato (S) & 0,1546 & $0,0178^{* *}$ & 0,9225 \\
E x S & 0,5503 & $0,0105^{* *}$ & 0,7540 \\
\hline Estaca basal & $1,97 \mathrm{a}$ & 1,19 & $23,88 \mathrm{a}$ \\
Estaca mediana & $1,16 \mathrm{a}$ & 0,29 & $11,29 \mathrm{~b}$ \\
Estaca apical & $0,85 \mathrm{~b}$ & 0,20 & $10,11 \mathrm{~b}$ \\
\hline Areia & $1,10 \mathrm{a}$ & 0,79 & $15,38 \mathrm{a}$ \\
Vermiculita & $1,55 \mathrm{a}$ & 0,32 & $14,81 \mathrm{a}$ \\
\hline CV(\%) & 14,92 & 11,90 & 25,79 \\
\hline
\end{tabular}

Médias seguidas de letras iguais na coluna não diferem entre si pelo Teste de Tukey ao nível de significância de 5\%. Means followed by equal letters in the column do not differ from each other by the Tukey test at the significance level of 5\%. Source: Author's research data.

Tabela 2a. Desdobramento da interação dos fatores estacas e substratos para a variável massa da matéria seca das raízes. Ilha Solteira - SP, 2011. Unfolding of the interaction of the factors cuttings and substrates for the dry matter mass variable of the roots. Ilha Solteira - SP, 2011.

\begin{tabular}{lccc}
\hline & \multicolumn{3}{c}{ Estacas } \\
\cline { 2 - 4 } Substrato & Basal & Mediana & Apical \\
\hline Areia & $1,86 \mathrm{a} \mathrm{A}$ & $0,33 \mathrm{~b} \mathrm{~A}$ & $0,19 \mathrm{~b} \mathrm{~A}$ \\
Vermiculita & $0,52 \mathrm{a} \mathrm{B}$ & $0,24 \mathrm{a} \mathrm{A}$ & $0,21 \mathrm{a} \mathrm{A}$ \\
\hline
\end{tabular}

Médias seguidas de letras minúsculas distintas na linha e maiúsculas na coluna diferem entre si pelo Teste de Tukey ao nível de significância de 5\%. Means followed by equal letters in the column do not differ from each other by the Tukey test at the significance level of $5 \%$.

A análise da interação entre tipos de substratos e estacas (Tabela 2a) para MMSR permitiu observar que aos 75 d.a.e. ocorreu efeito significativo para essa fonte de variação. Pela análise do desdobramento da interação estacas x substratos para MMSR verifica-se que 
quando utilizado o substrato areia as estacas basais apresentaram maiores valores de MMSR quando comparadas aos demais tipos de estacas. Por outro lado, não houve diferença significativa entre os diferentes tipos de estacas no substrato vermiculita. Apenas para as estacas basais o tipo de substrato utilizado influenciou na MMSR. Neste sentido, Feike et al. (2007) testando diferentes tipos de estacas em diferentes tipos de substratos e com aplicação de hormônios relatam que a variação no substrato não apresentou qualquer efeito assim como o tratamento das estacas com hormônios. As estacas basais apresentaram maiores valores de massa da matéria seca de raízes, número de raízes e porcentagem de enraizamento.

O número de brotos ou brotação é uma característica muito importante para tratamentos que envolvem pegamento em sistema de propagação vegetativa. $\mathrm{O}$ número de brotos de pinhão manso foi afetado significativamente pelos tratamentos utilizados no presente trabalho (Tabela 3).

Tabela 3. Valores de $\mathrm{p}>\mathrm{F}$ e teste de comparação de médias para número de brotos por estaca de pinhão manso obtidos em função dos tratamentos com diferentes tipos de estacas e substratos. Ilha Solteira - SP, 2011. Values of $p>F$ and test of comparison of averages for number of shoots by stakes of Jatropha curcas L. obtained as a function of treatments with different types of cuttings and substrates.

\begin{tabular}{lccc}
\hline FV & 21 dias & 32 dias & 75 dias \\
\hline Tipo de estaca $(\mathrm{E})$ & $0,0000^{* *}$ & $0,0001^{* *}$ & $0,0001^{* *}$ \\
Substrato $(\mathrm{S})$ & 0,0647 & $0,0100^{* *}$ & 0,5066 \\
E x S & $0,0047^{* *}$ & 0,0902 & 0,0796 \\
\hline Estaca basal & 4,53 & $4,21 \mathrm{a}$ & $3,42 \mathrm{a}$ \\
Estaca mediana & 3,41 & $3,46 \mathrm{~b}$ & $3,22 \mathrm{a}$ \\
Estaca apical & 1,24 & $1,36 \mathrm{c}$ & $1,27 \mathrm{~b}$ \\
\hline Areia & 3,25 & $3,29 \mathrm{a}$ & $2.75 \mathrm{a}$ \\
Vermiculita & 2,86 & $2,73 \mathrm{~b}$ & $2,52 \mathrm{a}$ \\
\hline CV $(\%)$ & 4,99 & 5,61 & 10,85 \\
\hline
\end{tabular}

Médias seguidas de letras iguais na coluna não diferem entre si pelo Teste de Tukey ao nível de significância de 5\%. Means followed by equal letters in the column do not differ from each other by the Tukey test at the significance level of $5 \%$.

Pode-se observar que as estacas basais apresentaram o maior número de brotos nas avaliações realizadas aos 21 e 32 dias, no entanto os valores não diferiram dos apresentados para o número de brotos das estacas medianas aos 75 dias, pois nem todos os brotos das estacas basais se desenvolveram, ocorrendo morte de alguns deles. Já as estacas apicais foram as que apresentaram o menor número de brotos em todas as avaliações, pois embora tivessem um maior número de gemas diferenciadas e maior quantidade de auxinas para promover a brotação, tinham também um menor número de reservas para fazer com que estas auxinas se expressassem. Fachinello et al. (2005) relatam que a auxina necessita de uma fonte de carbono para a biossíntese de proteínas e ácidos nucléicos.

Quanto ao tipo de substrato utilizado para estaqueamento, pode-se verificar que aos 32 d.a.e as estacas instaladas em areia apresentaram o maior número de brotos/estaca em relação às estacas instaladas em vermiculita, no entanto este fato não foi observado ao final do 
experimento. Tal fato pode ter ocorrido em decorrência da morte de algumas estacas instaladas em areia.

Pode-se constatar que aos 21 dias após o plantio, ocorreu interação entre tipo de estaca e substrato utilizado, sendo que somente para estacas basais o substrato vermiculita proporcionou um menor valor médio de brotos formados (Tabela 3a). Por outro lado, pode-se verificar que as estacas basais proporcionaram o maior valor de número de brotos quando o substrato utilizado foi areia. Quando o substrato utilizado foi vermiculita, as estacas basais e as estacas medianas proporcionaram valores similares de número de brotos, porém superiores aos valores obtidos para as estacas apicais. Severino et al. (2011) relatam que plantas originadas de estacas obtidas a partir da base do ramo originam mais estruturas (brotos e folhas) do que estacas originadas a partir do meio e do ápice dos ramos. Os autores obtiveram 5,7 brotos/estaca utilizando estacas basais e 2,3 brotos/estaca utilizando estacas apicais. De acordo com os autores, o número de raízes e brotos são características relacionadas com o desenvolvimento inicial da planta. No presente trabalho pode-se observar que estacas originadas a partir da base e do meio do ramo foram as que originaram o maior número de brotos.

Tabela 3a. Desdobramento da interação dos fatores estacas e substratos para a variável número de brotos. Ilha Solteira - SP, 2011. Unfolding of interaction of stakes and substrates for the variable of shoots number. Ilha Solteira - SP, 2011.

\begin{tabular}{lclc}
\hline & \multicolumn{3}{c}{ Estacas } \\
\cline { 2 - 4 } Substrato & Basal & Mediana & Apical \\
\hline Areia & 5,22 a A & $3,33 \mathrm{~b} \mathrm{~A}$ & $1,20 \mathrm{c} \mathrm{A}$ \\
Vermiculita & $3,83 \mathrm{a} \mathrm{B}$ & $3,49 \mathrm{a} \mathrm{A}$ & $1,28 \mathrm{~b} \mathrm{~A}$ \\
\hline
\end{tabular}

Médias seguidas de letras minúsculas distintas na linha e maiúsculas na coluna diferem entre si pelo Teste de Tukey ao nível de significância de 5\%. Means followed by equal letters in the column do not differ from each other by the Tukey test at the significance level of $5 \%$.

Via de regra, o número de folhas com mais de dois centímetros é uma variável importante, pois determina o bom pegamento de estacas em seu ambiente de crescimento. No presente estudo, pode-se constatar efeito significativo para a interação tipo de estaca e tipo de substrato, tanto aos 21 como aos 32 dias após a instalação do experimento (Tabela 4).

Aos 75 dias após a instalação do experimento, pode-se verificar que as estacas basais propiciaram um número de folhas superior àqueles verificados com a utilização de estacas medianas e apicais (Tabela 4), possivelmente pelo maior acúmulo de reservas nas estacas basais em relação às demais. Por outro lado, não foi verificada diferença significativa entre estacas medianas e estacas apicais para essa variável, assim como não houve diferença entre a utilização de areia ou vermiculita. Araujo et al. (2009), em estudo sobre enraizamento de mini estacas de pinhão manso com a utilização de reguladores, relatam média de 6,15 folhas/estaca para estacas herbáceas e 23,47 folhas/estaca para estacas lenhosas, valores estes muito maiores do que os apresentados no presente trabalho. Lima et al. (2010), descrevem um aumento no número de folhas, área foliar e massa da matéria seca da parte aérea com o incremento do tamanho das estacas, assim sendo, estimaram que o maior crescimento das plantas ocorre em estacas de comprimento em torno de $22 \mathrm{~cm}$, valor este bem próximo ao utilizado no presente experimento. 
Tabela 4. Valores de $\mathrm{p}>\mathrm{F}$ e teste de comparação de médias para número de folhas de pinhão manso maiores que $2 \mathrm{~cm}$ obtidos em função de tratamentos com diferentes tipos de estacas e substratos. Ilha Solteira - SP, 2011. Values of $p>F$ and test of comparison of averages for number of Jatropha curcas L. leaves greater than $2 \mathrm{~cm}$ obtained as a function of treatments with different types of cuttings and substrates. Ilha Solteira - SP, 2011.

\begin{tabular}{lccc}
\hline FV & 21 dias & 32 dias & 75 dias \\
\hline Tipo de estaca $(\mathrm{E})$ & $0,0001^{* *}$ & $0,0001^{* *}$ & $0,0008^{* *}$ \\
Substrato (S) & 0,2929 & $0,0001^{* *}$ & 0,4203 \\
E x S & $0,0133^{* *}$ & $0,0146^{* *}$ & 0,2035 \\
\hline Estaca basal & 4,03 & 8,33 & $8,41 \mathrm{a}$ \\
Estaca mediana & 1,78 & 4,01 & $5,12 \mathrm{~b}$ \\
Estaca apical & 1,29 & 2,21 & $4,01 \mathrm{~b}$ \\
\hline Areia & 2,26 & 3,56 & $5,68 \mathrm{a}$ \\
Vermiculita & 2,47 & 6,14 & $6,02 \mathrm{a}$ \\
\hline CV $(\%)$ & 15,16 & 12,81 & 14,41 \\
\hline
\end{tabular}

Médias seguidas de letras iguais na coluna não diferem entre si pelo Teste de Tukey ao nível de significância de 5\%. Means followed by equal letters in the column do not differ from each other by the Tukey test at the significance level of $5 \%$.

Tabela 4a. Desdobramento da interação dos fatores estacas e substratos para a variável número de folhas aos 21 e 32 dias após a instalação. Ilha Solteira - SP, 2011. Unfolding of the interaction of the stakes and substrates factors for the variable of leaves number at 21 and 32 days after installation.

\begin{tabular}{lccc}
\hline & \multicolumn{3}{c}{ Estacas (21 dias) } \\
\cline { 2 - 4 } Substrato & Basal & Mediana & Apical \\
\hline Areia & 4,88 a A & $0,95 \mathrm{~b} \mathrm{~B}$ & $0,96 \mathrm{~b} \mathrm{~A}$ \\
Vermiculita & 3,18 a A & $2,60 \mathrm{a} \mathrm{A}$ & 1,63 a A \\
\hline \multicolumn{4}{c}{ Estacas (32 dias) } \\
\hline Areia & 7,98 a A & $1,69 \mathrm{~b} \mathrm{~B}$ & $1,01 \mathrm{~b} \mathrm{~B}$ \\
Vermiculita & 8,68 a A & $6,34 \mathrm{a} \mathrm{A}$ & $3,41 \mathrm{~b}$ A \\
\hline
\end{tabular}

Médias seguidas de letras minúsculas distintas na linha e maiúsculas na coluna diferem entre si pelo Teste de Tukey ao nível de significância de 5\%. Means followed by equal letters in the column do not differ from each other by the Tukey test at the significance level of $5 \%$.

Desta forma, quando se avalia o tipo de substrato em função do tipo de estaca (Tabela 4 a) aos 21 dias após a instalação do experimento, pode-se constatar que somente para estacas medianas o substrato vermiculita proporcionou valores superiores de número de folhas. Da mesma forma, 32 dias após a instalação do experimento, tanto para estacas medianas como para estacas apicais, o substrato vermiculita proporcionou um número maior de número de folhas. Em relação ao tipo de estaca, pode-se constatar que aos 21 dias quando instaladas em areia as estacas basais foram as que apresentaram maior número de folhas, no entanto quando instaladas em vermiculita não diferiram significativamente em relação ao número de folhas apresentado. Tal resultado pode ser explicado pelo fato das estacas basais e medianas apresentarem maior quantidade de reservas para o desenvolvimento folhas e as estacas apicais possuírem maior quantidade de auxinas que seriam responsáveis por uma maior indução na emissão de novas brotações e desenvolvimento de folhas. Aos 32 dias após o estaqueamento, 
verificou-se que quando estaqueadas em areia as estacas basais apresentaram maior número de folhas quando comparadas às demais. No entanto, quando estaqueadas em vermiculita as estacas basais e medianas não tiveram diferenças significativas em relação ao número de folhas apresentado e as estacas apicais foram as que apresentaram o menor número de folhas. Tal fato provavelmente pode ser explicado pelas características dos substratos, pois a areia é totalmente inerte enquanto a vermiculita permite algumas trocas catiônicas, possibilitando um melhor desenvolvimento das estacas.

\section{CONCLUSÕES}

A utilização de vermiculita permitiu a obtenção de valores para porcentagem de estacas vivas muito próximas para estacas basais $(82,5 \%)$, medianas $(80,0 \%)$ e apicais $(60,0 \%)$.

As estacas basais, independentemente do tipo de substrato são aquelas que permitem uma maior obtenção de porcentagem de estacas vivas, massa da matéria seca das brotações e das raízes, comprimento dos brotos, número de brotos e número de folhas com mais de 2,0 $\mathrm{cm}$.

O substrato vermiculita proporciona uma maior porcentagem de estacas vivas e número de folhas.

A massa da matéria seca de raízes é maior quando da utilização do substrato areia.

\section{AGRADECIMENTOS}

À Petrobrás Biocombustível pela concessão da bolsa.

\section{REFERÊNCIAS BIBLIOGRÁFICAS}

ALVES, J. M. A.; SILVA, A. A. S. S. R. G.; LOPES, G. N.; SMIDERLE, O. J.; UCHÔA, S.C.P. Pinhão-manso: uma alternativa para produção de biodiesel na agricultura familiar da amazônia brasileira. Agro@mbiente On-line, Boa Vista, v. 2, n. 1, p.57-68, 2008. Disponível em: <http://revista.ufrr.br/index.php/agroambiente/article/view/160>. Acesso em: 28 mar. 2010 .

ARAUJO, E. C. E.; FILHO, C. H. A. M.; AZEVEDO, D. M. P. de. Interação entre doses de reguladores e consistência do ramo no enraizamento de miniestacas de pinhão-manso. In: CONGRESSO BRASILEIRO DE PESQUISAS DE PINHÃO MANSO, 1, 2009, Brasília, DF. Anais... Brasília, DF: Embrapa Bioenergia, 2009. 4 p. 1 CD-ROM.

BARROS, A. P. B. Vias de propagação do pinhão manso (Jatropha curcas L.). In: CONGRESSO BRASILEIRO DE PLANTAS OLEAGINOSAS, ÓLEOS, GORDURAS E BIODIESEL, 4., 2007, Varginha. Anais... Lavras: UFLA, 2007. 6 p.

CENTURION, J. F. Balanço hídrico na região de Ilha Solteira. Científica, Jaboticabal, v. 10, n. 1, p.57-61, 1982. 
DIAS, L. A. S.; LEME, L. P.; LAVIOLA, B. G.; PALLINI FILHO, A.; PEREIRA, O. L.; CARVAlHO, M.; MANFIO, C. E.; SANTOS, A. S.; SOUSA, L. C. A.; OLIVEIRA, T. S.; DIAS, D. C. F. S. Cultivo de pinhão manso (Jatropha curcas L.): para produção de óleo combustível. Viçosa: Ed. UFV, 2007. 40 p.

FACHINELlO, J. C.; HOFFMANN, A.; NACHTIGAL, J. C.; KERSTEN, E.; FORTES, G. R. L. Propagação de plantas frutíferas de clima temperado. 2. ed. Pelotas: UFPel, 1995. $178 \mathrm{p}$.

FACHINELlO, J. C.; HOFFMANN, A.; NACHTIGAL, J. C. (Ed.). Propagação de plantas frutíferas. Brasília, DF: Embrapa Informação Tecnológica, 2005. 221 p.

FEIKE, T.; WEIS, K.; CLAUPEIN, W.; MUELLER, J. Propagation of physic nut (Jatropha curcas L.) on Leyte Island, Philippines. In: CONFERENCE ON INTERNATIONAL AGRICULTURAL RESEARCH FOR DEVELOPMENT, 2007, Proceedings... Witzenhausen: University of Kassel/ University of Göttingen, 2007. p. 1-6.

FERREIRA, D. F. Sisvar: a computer statistical analysis system. Ciência e Agrotecnologia, Lavras, v. 35, n. 6, p.1039-1042, 2011.

HARTMANN, H. T.; KESTER, D. E.; DAVIES, F. T.; GENEVE, R. L. Plant propagation: principles and practices. 7. ed. New Jersey: Prentice Hall, 2004. 880 p.

HELLER, J. Physic nut. Jatropha curcas L. Promoting the conservation and use of underutilized and neglected crops. Rome: Institute of Plant Genetics and Crop Plant Research, Gatersleben/International Plant Genetic Resources Institute, 1996. 66 p.

KORNDÖRFER, G. H.; PRIMAVESI, O.; DEUBER, R. Crescimento e distribuição do sistema radicular da cana-de-açúcar em solo LVA. Boletim Técnico Copersucar, Piracicaba, v. 47, p.32-36, 1989.

LIMA, R. L. S.; SEVERINO, L. S.; PEREIRA, W. E.; LUCENA, A. M. A. de; GHEYI, H. R.; ARRIEL, N. H. C. Comprimento das estacas e parte do ramo para formação de mudas de pinhão-manso. Revista Brasileira de Engenharia Agrícola e Ambiental, Campina Grande, v. 14, n. 11, p.1234-1239, 2010.

MOREIRA, E. R. Métodos de propagação do pinhão manso (Jatropha curcas L.). 2013. 116 f. Tese (Doutorado em Agronomia - Especialidade em Sistemas de Produção) Faculdade de Engenharia, Universidade Estadual Paulista, Ilha Solteira, 2013.

NOOR CAMELLIA, N. A.; THOHIRAH, L. A.; ABDULLAH, N. A. P.; MOHD KHIDIR, O. Improvement on rooting quality of Jatropha curcas using indole butyric acid (IBA). Research Journal of Agriculture and Biological Sciences, Jordan, v. 5, n. 4, p.338-343, 2009.

PUTTEN, E. van der; FRANKEN, Y. J., JONGH, J. de. Manual de Jatropha: versíon en español: sección 1: datos generales de la Jatropha. FACT Foundation, p. 7-14, 2009. Disponível em: <http://www.jatropha.pro/PDF\%20bestanden/FACT\%20Jatropha\%20Handbook\%20\%20Espanol.pdf $>$. Acesso em: 25 maio 2013. 
SEVERINO, L.S.; LIMA, L.S.; LUCENA, A.M.A.; FREIRE, M.A.O.; SAMPAIO, L.R.; VERAS, R.P.; MEDEIROS, K.A.A.L.; SIFIATTI, V.; ARRIEL, N.H.C. Propagation by stem cuttings and root system structure of Jatropha curcas. Biomass and Bioenergy, Kidlington, v. 35, n. 7, p.3160-3166, 2011. 